\title{
KNOWLEDGE ON CANCER PAIN MANAGEMENT AMONG NURSES OF HOSPITAL IN LALITPUR
}

\author{
Minu Duwal \\ TUIOM, \\ Biratnagar Nursing Campus Biratnagar Nepal
}

\begin{abstract}
Pain management is the fundamental human right for patients to have freedom from pain nurses are the most important parts in assessment and management of pain as they spend more time with patients. The main objectives of the study were to assess the level of knowledge about the cancer pain management among the nurses working in oncology hospital of Lalitpur.

A descriptive cross sectional study was carried out among 75 nurses by using Census method in selected oncology hospital of central region via self-administered semistructured questionnaire. Non probability purposive sampling technique was used. Descriptive statistics i.e., mean, median and standard deviation was used to assess the level of knowledge. Inferential statistics i.e., Chi-square test was used to find out the association between dependent and independent variables.

The findings of the study showed that out of 75 nurses more than half $(54.7 \%)$ had completed bachelor degree and $60 \%$ were unmarried and all most of $(82 \%)$ had work experience one to five years. Less than half $(38.7 \%)$ nurses had good knowledge where as 37.3 had average knowledge and $24 \%$ had poor knowledge on cancer management. All most of the nurses knew that intravenous opoids is best for severe onset of cancer pain.

The study concluded that most of the nurses have adequate knowledge on cancer pain management and only few of them have taken special training on it.
\end{abstract}

Key words: Nurses, Knowledge, cancer pain, management.

\section{INTRODUCTION}

Nepal is a small landlocked country, between the world's two largest growing economics. The recent republic nation of Nepal is renowned for the Himalayas and also has diversity in religion, culture, and ethnicity. Given its small size of 147,181 square kilometers, the country has a population of approximately 30 million and with the estimated cancer incidence of 50, 000 -70,000 per year (Census, 2011).

Pain is regarded as a fifth vital sign Nurses have an important of pain assessment and management. Under treatment of pain due to inadequate knowledge is a significant clinical problem

\author{
Saraswati Basnet \\ Lecturer, TUIOM, \\ Biratnagar Nursing Campus, Morang, Nepal
}

leading to inappropriate and inadequate pain practices. Pain is one of the most important symptoms that bring patients to the hospital. It is an unpleasant sensory and emotional experience associated with actual or potential tissue damage. it is fundamental human right for patients to have freedom from pain. Nurses are the most important parts in assessment and management of pain as they spend more time with patients (Jemal, Bray, Centre, Ferlay, ward, \& Forman, 2011).

Cancer is considered one of leading causes of death globally, World Health Organization (WHO, 2014). Bray, Centre, Ferlay, ward, \& Forman, (2011) estimated that by the year 2030 there will be 21.4 million new patients diagnosed with cancer annually, in the advanced stages, where pain is the most upsetting symptom for patient with cancer (Yazdani \& Abdi, 2014).

The American Cancer society declared that 60 percent of patients who received treatment for cancer experienced moderate to severe pain the percentage increased up to 90 percent in the advanced stages of cancer (Siegel, Naishadhan \& Jemal, 2013).

Poor knowledge and negative attitudes towards pain management were reported as one of the most common barriers of to effective pain management (AL Quire \& $\mathrm{Al}$ Khalaieh, 2014). Cancer pain is a multi-dimensional syndrome with a combination of acute and chronic pain that causes physical, psycho-social, behavioral, emotional and spiritual problems, resulting in adverse effects on patients' quality of life (King, Forbes, \& Hanks, 2011).

Nurses are the first health care professional's patient encounter; they must be thoroughly familiar with the assessment strategies and have broad knowledge and understanding of common cancer pain issue and their management (Vallerand, Collins, Templin, \& Hasenan, 2007). Managing pain in patients with cancer is possible; evidence indicates that 80 to 90 percent of pain can be relieved by correctly following international guides for managing (Foley, 2012). 


\section{International Journal of Engineering Applied Sciences and Technology, 2019 Vol. 4, Issue 7, ISSN No. 2455-2143, Pages 95-98 \\ Published Online November 2019 in IJEAST (http://www.ijeast.com)}

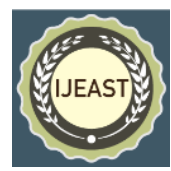

\section{RESEARCH METHODOLOGY}

Research design: a hospital based cross sectional descriptive research design will be adopted to identify the knowledge on cancer pain management among the nurses. Research Setting and Population: the study was conducted at Nepal Cancer and Research Centre, Lalitpur. It is the oncology hospital with the all cancer services. The population of the study was all registered nurses working and who are directly involved in the patient's care be included. Sampling: Non Probability purposive sampling technique was used to select appropriate sample. All registered nurses working and who are directly involved in the patient's care was included in the study. The total sample size was included only 50 and census method was used.

Instrumentation: a self-administered structured questionnaire as per the objectives of the study was developed with the help of extensive literature review, consultation with colleagues, other expert and researcher's knowledge and experience. It consists of two parts. Part I: Demographic information. Part II: Questions related to existing knowledge on cancer pain management among nurses. Data collection procedure: ethical clearance was taken from concerned authorities and subject was chosen based on inclusion criteria. Purpose of the study was explained and verbal and written consent was obtained from the respondents prior to the data collection. Questionnaires were distributed to respondents and researcher herself collects the data. Data Analysis Procedure: Data was checked for completeness and consistency. The collected data were organized and coded and entered in Statistical Package for Social Science (SPSS 16) version. The data were analyzed by using descriptive statistics like frequency, percentage, mean and standard deviation. The knowledge of the respondents were categorized as good knowledge level that score more $75 \%$, average knowledge as equal to $50 \%-75 \%$ and poor knowledge as less than $50 \%$ of obtained score.

\section{RESEARCH RESULTS DISCUSSION AND CONCLUSION}

3.1 Socio-Demographic Variable: The study result reveals that more than half $(54.7 \%)$ had completed bachelor in nursing and least $(1.3 \%)$ had completed master in nursing. sixty percent of nurses were unmarried. regarding working area $26.7 \%$ were surgical ward and least $(8.2 \%)$ were hematology ward. Almost of all (82\%) of nurses' working experience had one to five years and only least $(17.3 \%)$ had above 5 years. Only twenty five percent had received special training of cancer management.

3.2 Knowledge Related to Pain Management: The study result reveals that more than half $(53.3 \%)$ had answered caring nurses is most accurately judged by caring nurses. almost of (82.7) answered it is necessary to assess the level of patient pain after patient reporting pain. hundred percent of nurses answered to assess patients pain before giving pain medication. more than half $(62.7 \%)$ of nurses assess patient's pain by asking patient, by examining patient and by using pain scale.

3.3 Knowledge Related to Use of Medication: The result shows that less than half $(42.7 \%)$ had answered the subcutaneous route as best of medication for controlling chronic pain at least $(16 \%)$ of nurses answered I/M route as best route and almost $(100 \%)$ of nurses said that intravenous is route for severe and sudden onset of cancer pain. more than half $(60 \%)$ of nurses response as NSAID, Opioid and adjuvant drugs are useful medication for cancer pain and least (4\%) nurses response adjuvant drugs as useful medication for cancer pain.

3.4 Knowledge Related to Use of WHO Analgesics Ladder: The result shows that more than half $(68 \%)$ revealed that nurses know about WHO analgesics ladder \& less than (32\%) said they do not know WHO ladder and more than $(68 \%)$ nurses, know WHO ladder. more than third fourth $(78.4 \%)$ answered it contains Who have 3 steps and only least $(21 \%)$ said having four steps.

\subsection{Knowledge Related to Nursing Management}

$\mathrm{n}=\mathbf{7 5}$

\begin{tabular}{|c|c|c|}
\hline \multicolumn{3}{|c|}{$\mathrm{n}=12$} \\
\hline Responses & Frequency & Percentages \\
\hline \multicolumn{3}{|l|}{$\begin{array}{l}\text { Method to decrease } \\
\text { pain }\end{array}$} \\
\hline Hot and cold application & 6 & 8 \\
\hline Psychotherapy & 19 & 25.3 \\
\hline All of the above & 50 & 66.7 \\
\hline \multicolumn{3}{|l|}{ Psychological pain } \\
\hline Diversion and relaxation & 74 & 98.7 \\
\hline Don’t know & 1 & 1.3 \\
\hline \multicolumn{3}{|l|}{ Other methods } \\
\hline Radiation therapy & 38 & 50.7 \\
\hline Placebo therapy & 15 & 20 \\
\hline Group therapy & 17 & 22.7 \\
\hline Don't know & 5 & 6.6 \\
\hline \multicolumn{3}{|l|}{$\begin{array}{l}\text { Mental distraction for } \\
\text { pain relief }\end{array}$} \\
\hline Agree & 41 & 54.7 \\
\hline Partially agree & 34 & 43.3 \\
\hline \multicolumn{3}{|l|}{ Nurses Role } \\
\hline Pain management & 75 & 100 \\
\hline
\end{tabular}




\section{International Journal of Engineering Applied Sciences and Technology, 2019 Vol. 4, Issue 7, ISSN No. 2455-2143, Pages 95-98 \\ Published Online November 2019 in IJEAST (http://www.ijeast.com)}

Above table of shows that more than half (66.7) of the nurse pain intensity is decreased by hot and cold application, psychotherapy and counseling. In psychological pain intervention, almost (98.7\%) of nurses answered diversion and relaxation. in other methods of pain management more than half $(50.7 \%)$ answered radiation therapy. In nurses role in pain management almost $(100 \%)$ of nurses answered that to assess the patient's pain give medicine as prescribed.

\subsection{Level of Knowledge on Cancer Pain Management}

\begin{tabular}{lll}
\hline Knowledge & n=75 & \\
\hline Good $(>\mathbf{7 5} \%)$ & 29 & Percentage \\
Average (50-75\%) & 28 & 38.7 \\
Poor $(<\mathbf{5 0} \%)$ & 18 & 37.3 \\
\hline
\end{tabular}

Table 3.6 shows that less than half $(38.7 \%)$ of nurses had good knowledge where as only $37.3 \%$ of nurses had average knowledge and $24 \%$ of nurses had poor knowledge on cancer pain management.

\section{DISCUSSION}

This study revealed that $38.7 \%$ of nurses have good knowledge on cancer pain management which is similar to the study conducted by (getachew \& kassa, 2014) shows that $37.1 \%$ of respondents answered correctly. This study revealed that $25.3 \%$ of nurses have received special training of cancer pain management, which is nearly consistently to the study conducted by (omran, qudire, \& hayaek, 2014) which revealed that $7.5 \%$ had undertaken professional training on cancer pain management that is better training practice than study conducted previously.

Similarly present study finding revealed that almost (100\%) of nurses knew that intravenous opioid is best for severe onset of cancer pain which is similar to the study done by (Vickers, 2011) reported that majority $78.7 \%$ respondents reported strong opiods are given by intravenous for sudden onset of pain. study finding also shows that nurses used pain scale instrument to assess the level of pain which is similar study done by (Alhassan, Ahemed, \& Bannaga, 2017) reported that $20 \%$ nurses use Visual Analogue Scale (VAS) for pain management. this study result shows that $76 \%$ of nurses judged patient's pain effectively. in this study $38.7 \%$ nurses had good knowledge of cancer pain management which is consistent with the finding of the study done by (Dunwoody, Krenzischek, Pasero, Rathmell, \& Polomano, 2008) in which reported that $58 \%$ of nurses have good knowledge on cancer pain management.

\section{CONCLUSION}

This study concluded that more than half of nurses had not received special training on cancer pain management. So the emphasis must be given on special training to nurses working on oncology unit for proper pain management.

\section{Acknowledgement}

I would like to express my sincere gratitude to the Medical Superintendent, Koshi-Zonal Hospital for constant inspiration, academic support, and providing platform for research work. I would my sincere gratitude to this research, supervisor (corresponding author) I am very grateful to Biratnagar Nursing campus, Koshi Zonal Hospital and all the respondents for their valuable information and cooperation.

\section{REFERENCE}

1. Jemal, A., Bray, F., Centre, M. M., Ferlay, J., Ward, E., \& Forman, D. (2011). Global Cancer Statistics. Cancer Journal of Clinical , 69-90.

2. Vallerand, A. H., Collins, B. B., Templin, T., \& Hasenan, S. (2007). Knowledge of and Barriers to pain Management in Caregivers of Cancer patients receiving Homecare. Cancer Nursing Journal , 3137.

3. King, S., Forbes, K., \& Hanks, G. (2011). A systematic review of the use of opioid medication for those with moderate to severe cancer pain and renal impairment: A European Palliative Care Research Collaborative opioid guidelines project. Journal of palliative Nursing , 50-62.

4. ALQuire, M., \& AlKhalaieh, M. (2014). Jordanian nurses Knowledge and a Attitude Regarding Pain management. Journal of Pain Management Nursing , 220228.

5. Alhassan, M. A., Ahemed, F. E., \& Bannaga, A. A. (2017). Pain assessment and management: The knowledge, attitude and practice of Sudanese Paediatric Residents. Sudan Journal of paediatric , 25-29.

6. Getachew, R. N., \& Kassa, G. M. (2014). Nurses' Attitude, Practice and Barriers toward Cancer Pain Management, Addis Ababa, Ethiopia. Journal of Cancer science and therapy, 483-487.

7. ALQuire, M., \& AlKhalaieh, M. (2014). Jordanian nurses Knowledge and a Attitude Regarding Pain management. Journal of Pain Management Nursing , 220228. 
8. Vickers, N., (2011). Knowledge and Attitudes Regarding Pain among Surgical Nurses in Three Teaching Hospitals in Ireland.Dublin City University School of Nursing.

9. Dunwoody, C., Krenzischek, D., Pasero, C., Rathmell, J., \& Polomano, R. (2008). Assessment, physiological monitoring, and consequences of inadequately treated acute pain. Journal of Perinesthesia Nurses, 15-27.

10. WHO. (2014). Global status Report on Non Communicable Diseases. Zeneva: WHO.

11. Yazdani, S., \& Abdi, S. (2014). Brief review: Pain management for cancer survivors: Challenges and opportunities. Canadian Journal of Anesthesia , 745-753.

12. Foley, K. M. (2014). Assessment of Pain in Patients with Cancer. London: Springer Netherlands. p.37-41

13. Yazdani, S., \& Abdi, S. (2012). Brief review: Pain management for cancer survivors: Challenges and opportunities. Canadian Journal of Anesthesia , 745-753.

14. Census, C. B. (2011). Nepal Demographic and Health Survey 2011. Kathmandu: Ministry of Health and Population, New ERA, and ICF International, Calverton, Maryland. 